\title{
Piezoelectric Energy Harvester for IoT Sensor Devices
}

\author{
Noor Pratama Apriyanto ${ }^{1}$, Eka Firmansyah², Lesnanto Multa Putranto ${ }^{3}$
}

\begin{abstract}
Limited battery power is a major challenge for wireless sensor network (WSN) in internet of things (IoT) applications, especially in hard-to-reach places that require periodic battery replacement. The energy harvesting application is intended as an alternative to maintain network lifetime by utilizing environmental energy. The proposed method utilized piezoelectricity to convert vibration or pressure energy into electrical energy through a modular piezoelectric energy harvesting design used to supply energy to sensor nodes in WSN. The module design consisted of several piezoelectric elements, of which each had a different character in generating energy. A bridge diode was connected to each element to reduce the feedback effect of other elements when pressure was exerted. The energy produced by the piezoelectric is an impulse so that the capacitor was used to quickly store the energy. The proposed module produced $7.436 \mu \mathrm{J}$ for each step and $297.4 \mu \mathrm{J}$ of total energy with pressure of a $45 \mathrm{~kg}$ load 40 times with specific experiments installed under each step. The energy could supply WSN nodes in IoT application with a simple energy harvesting system. This paper presents a procedure for measuring the energy harvested from a commonly available piezoelectric buzzer. The specific configurations of the piezoelectric and the experiment setups will be explained. Therefore, the output energy characteristics will be understood. In the end, the potentially harvested energy can be estimated. Therefore, the configuration of IoT WSN could be planned.
\end{abstract}

Keywords-Wireless Sensor Network, Internet of Things, Energy Harvesting, Piezoelectric.

\section{INTRODUCTION}

Wireless sensor network (WSN) is growing in the current internet of things (IoT) era. WSN applications have been used in many sectors such as industry, smart cities/buildings, health, agriculture, fisheries, and livestock for automation to increase productivity [1]-[3]. WSN consists of many sensor nodes installed in certain places, then they measure environmental parameters (such as temperature, humidity, sound, pressure, and motion) and transmit the data to the base station (BS) [2], [4]. Essential functions that must presence in WSN are sensing, data processing, data communication, and power supply [5], [6].

The challenges faced on the power supply side are related to performance and network lifetime. WSN generally uses batteries as its power supply due to the relatively low power requirements and the economic cost. However, shortcomings are found in the use of batteries in WSN, such as limited battery capacity and the need for battery replacement which is

1,2,3 Department of Electrical and Information Engineering, Faculty of Engineering, Universitas Gadjah Mada, Jln. Grafika No 2, Kampus UGM, Yogyakarta 55281 INDONESIA (phone: 0274552305; email: noor.pratama@mail.ugm.ac.id, eka.firmansyah@gmail.com,lesnanto@ugm.ac.id) sometimes hard to handle due to the location of WSN placement [1]-[5], [7], [8]. In addition, the sensor node performance is also affected by the quality of the power supply. Network latency and data reliability will generally increase when the energy consumption is reduced, causing a decrease in network quality of service (QoS) [9].

One of the efforts to overcome battery energy limitations and battery replacement problems is by utilizing energy harvesters [1]-[3], [5], [7], [9]. Energy harvesting technology is one of the most popular renewable energy research which has the advantage of producing clean energy. Energy harvesting collects energy from the environment and utilizes that energy by converting it into electrical energy, providing a certain amount of power for low-power electronic devices. On its development, energy harvesting methods can replace batteries as power supplies for low-power devices [10]. Energy sources that can be harvested include solar power, heat energy, and vibration energy [11]

The main topic of this paper is vibration energy harvesting. The harvested vibrations can be obtained from mechanical energy around us, such as daily human activities, transportation, infrastructure, industry, and environment [12] as shown in Table I. Piezoelectric is one method to convert vibration energy into electrical energy. The piezoelectric transducer is more efficient in energy conversion with a simple structure and various manufacturing types [11].

Fig. 1(a) shows the disk after polarization (poling). Piezoelectric works as a generator or converts mechanical energy into electrical energy when the piezoelectric element is given compression to generate an electrical voltage in the same direction as the polarity. Hence, the generated voltage has the same polarity as poling voltage, such as in Fig. 1(b). Meanwhile, when the piezoelectric element is stretched, electrical voltage is generated by controverting the voltage at the polarity. In other words, in disk stretched, generated voltage has polarity opposite that of poling voltage, as shown in Fig. 1(c). Piezoelectric can be utilized as an electrical motor or load when it is supplied by electrical voltage. It will lengthen if supplied by direct currents which has the same polarity as poling voltage, such as in Fig. 1(d). Additionally, piezoelectric will become shorten if supplied by electrical voltage controverting the polarity of that poling voltage, such as in Fig. 1(e) [13].

A piezoelectric speaker (buzzer) is a small-lightweight sound generator based on the piezoelectric principle. This ubiquitous device may be utilized as a generator. In [14] and [15], the energy was generated through the piezoelectric in the floor, using human activities. The energy obtained and monitored could be used as an alternative power supply for the automatic switch mechanism [15]. Another implementation of piezoelectric as an energy harvester is in [16], the energy harvested from the sidewalk could be used to supply energy for 
TABLE I

EVERYDAY SOURCES OF MECHANICAL ENERGY SURROUND US THAT CAN BE HARVESTED

\begin{tabular}{|l|l|}
\hline \multicolumn{1}{|c|}{ Type } & \multicolumn{1}{|c|}{ Sources } \\
\hline Human Body/Motion & $\begin{array}{l}\text { Breathing, blood flow/pressure, } \\
\text { exhalation, walking, arm motion, } \\
\text { finger. }\end{array}$ \\
\hline Transportation & $\begin{array}{l}\text { Aircraft, automobile, train, tires, track, } \\
\text { peddles, brakes, turbine engine, } \\
\text { vibration, noise. }\end{array}$ \\
\hline Transportation & $\begin{array}{l}\text { Bridges, roads, tunnels, farm, house } \\
\text { structure, control-switch, water-gas. }\end{array}$ \\
\hline Industry & $\begin{array}{l}\text { Motor, compressor, chiller, pumps, } \\
\text { fans, vibrations, cutting. }\end{array}$ \\
\hline Environment & $\begin{array}{l}\text { Wind, ocean current/ wave, acoustic } \\
\text { wave. }\end{array}$ \\
\hline
\end{tabular}

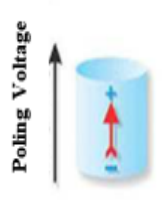

(a)

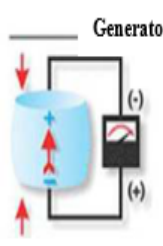

(b)

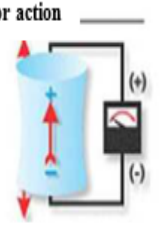

(c)

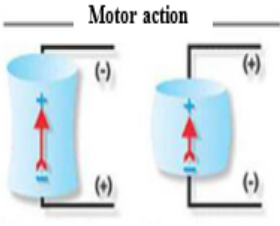

(d)

(e)
Fig. 1 (a) Disk after polarization (poling), (b) disk compressed, (c) disk stretched, (d) disk lengthens, and (e) disk shortens.

WSN. A similar principle also has been applied to harvest energy in the transportation systems [17]-[19], as a source to harvest the energy using piezoelectric. The harvested energy could be used to supply cellphone charging systems [17], IoTbased self-monitoring systems, and LED-assist drivers [18], as well as temperature monitoring [19].

In this paper, a $35 \mathrm{~mm}$ piezoelectric buzzer was used, as shown in Fig. 2. This type is widely used in energy harvesting research because it is easy to purchase at an affordable price. However, piezoelectric energy harvesters (PEH) have a shortcoming in the piezoelectric output inconsistency, both the voltage and the energy produced. Therefore, this study aims to determine the characteristics of the piezoelectric output voltage used as a reference for making power converters, besides knowing the amount of electrical energy that can be harvested. The study also aims to determine the electrical energy harvested from piezoelectric energy harvesting system (PEHS) so that it can be used to supply energy to sensor devices in the WSN.

\section{Methodology}

The method used was experimental method consisting of two measurements. The first measurement was the characteristic of the piezoelectric output voltage measurement. The second was the energy measurement which could be harvested from charging the capacitor.

\section{A. Piezoelectric Output Voltage Characteristics Measurement}

This test observes the output voltage response of the piezoelectric buzzer when given a load. Ten piezoelectric

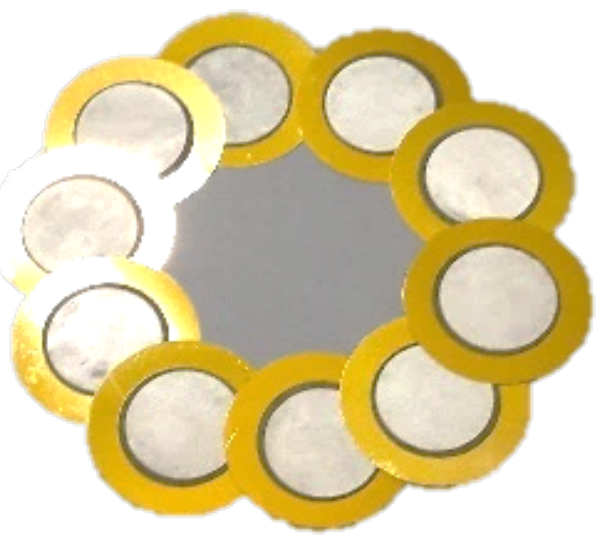

Fig. 2 Piezoelectric buzzer.

\section{Oscilloscope GW INSTEK GDS-2102}

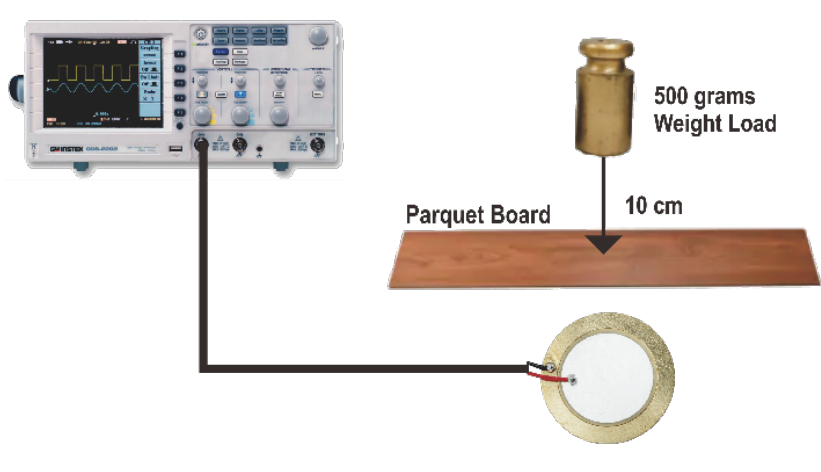

$35 \mathrm{~mm}$ Piezoelectric Buzzer

Fig. 3 Piezoelectric output voltage characteristic measurement scheme.

samples were used in this test. Each sample was mounted on a parquet board, and then the response data was taken ten times using an oscilloscope. The load used was 500 grams and dropped from a height of $10 \mathrm{~cm}$ from the parquet surface, as illustrated in Figure 3.

\section{B. Output Energy Measurement of Harvesting System}

This test observes the output energy of the PEHS through a capacitor charging mechanism. The energy source that comes from a human footstep is categorized as potential energy (Ep) and can be calculated using (1).

$$
E p=m \cdot g \cdot h
$$

where $m$ is the mass or human body weight in kilograms $(\mathrm{kg}), g$ is the earth's gravitational acceleration, which is 9.8 $\mathrm{m} / \mathrm{s}^{2}$, and $h$ is the height $/$ thickness of the parquet module to the ground in meters $(\mathrm{m})$. Fig. 4 illustrates the potential energy calculation with increasing mass $(m)$, height/thickness $(h)$, and potential energy. Purposed implementation, human activity in the form of footsteps is determined by body mass and is dynamic according to where it is implemented (offices, schools, pedestrians, etc.). The height/thickness adjusts to the surface where the PEH is implemented, for instance the surface of the floor or stairs. Based on (1), the potential energy will increase accordingly following the height/thickness increase.

The piezoelectric output voltage, which can have positive or negative polarity, could be categorized as an AC system. A 


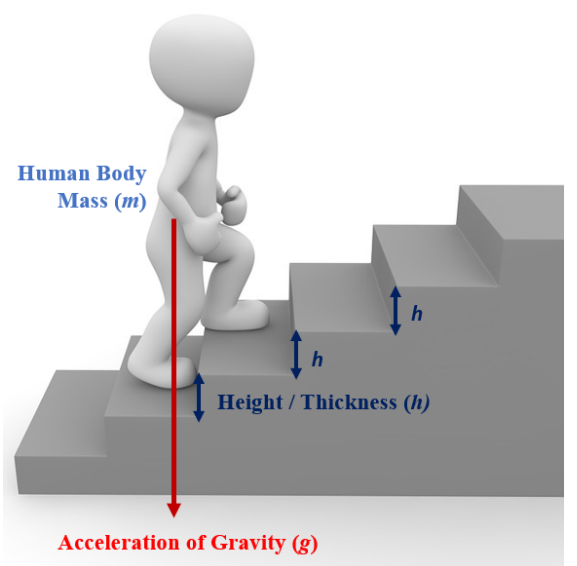

Fig. 4 Illustration of potential energy from human footsteps.

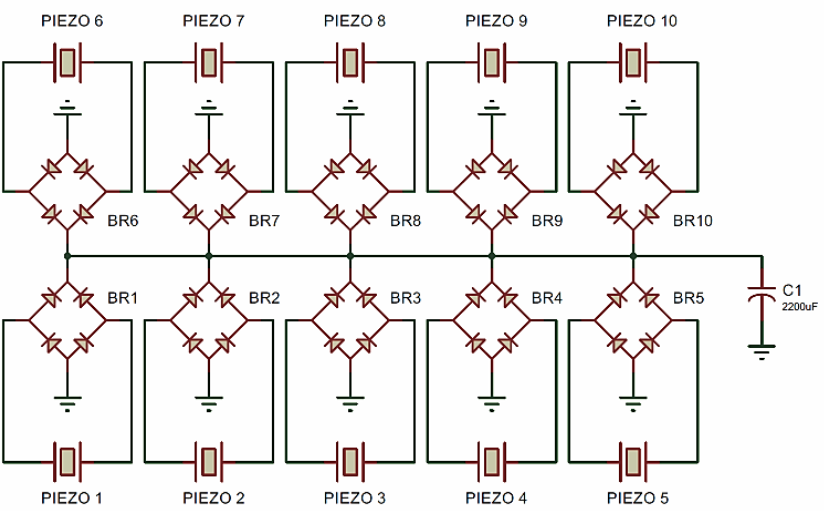

Fig. 5 Energy harvester circuit schematic.

bridge diode was used to adjust the output of each piezoelectric, so they did not interfere with each other. The energy harvester circuit consisted of ten piezoelectric elements connected in parallel to obtain a higher current with an equal voltage level for each element. Each element was connected to a KBP308 bridge diode as in the circuit scheme in Fig 5.

The circuit in Fig. 5 is arranged into an energy harvesting module. A parallel circuit of ten piezoelectric was attached to the bottom of the parquet with the dimension of $20 \times 30 \mathrm{~cm}$. Two acrylic resins with each dimension of $30 \mathrm{~cm}, 1 \mathrm{~cm}$ width, and $0.6 \mathrm{~cm}$ thickness were installed as an impact beam at the bottom of the piezoelectric element array to focus the received pressure and then spread the pressure to all the piezoelectric elements as illustrated in Fig. 6.

A capacitor with $2200 \mu \mathrm{F} / 16 \mathrm{~V}$ capacity was used at the capacitor charging test. The energy harvesting module was connected to a capacitor, and it was tested gradually to observe the amount of energy that could be generated. At every stage, the module was given a load of $45 \mathrm{~kg}$, and then it would be stepped on 40 times. The energy measurement started from one piezoelectric element, without connecting it with the other nine elements. Afterward, the PEH module would be getting a load pressure. Measurement was continued by adding/connecting a piezoelectric element configured in parallel with the previous element step by step. The energy data of the PEH module was obtained for a parallel configuration of two elements to parallel

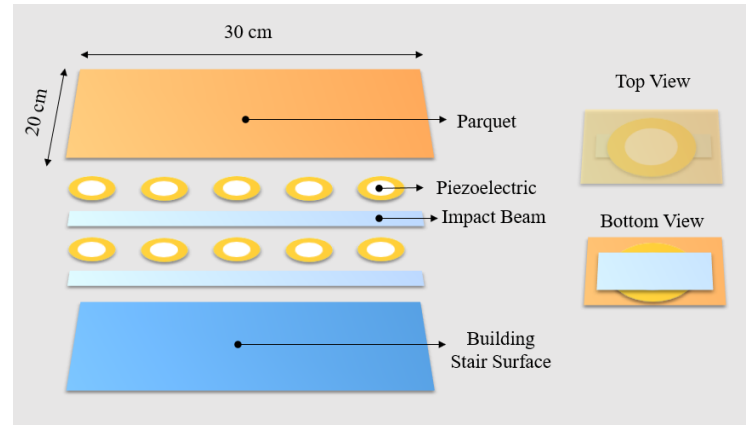

Fig. 6 The energy harvester module design.

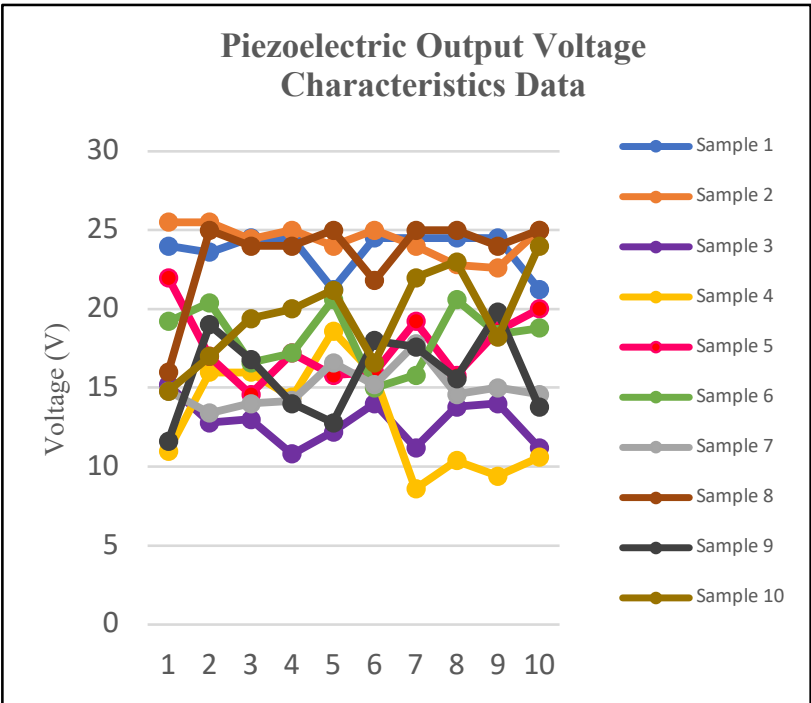

Fig. 7 Measurement data graph of the piezoelectric output voltage characteristics.

configuration of ten elements. The energy obtained from the energy harvesting system module can be formulated as in (2).

$$
W=\frac{C V^{2}}{2}
$$

where $W$ is the energy stored in the capacitor in joules $(\mathrm{J})$. Variable $C$ is the capacitor capacity in farads $(\mathrm{F})$, and variable $V$ is the capacitor voltage in volts $(\mathrm{V})$. Thus, if the capacitor voltage is greater, the energy stored or obtained is also greater.

\section{RESULT AND DISCUSSION}

\section{A. Measurement Result of Piezoelectric Output Voltage Characteristics}

The voltage generated from testing ten piezoelectric samples was a minimum voltage of $8 \mathrm{~V}$ and a maximum voltage of 25 $\mathrm{V}$, as shown in Fig. 7. The voltage would appear after the piezoelectric received a load and would disappear or zero when there was no pressure change in the piezoelectric. Therefore, the piezoelectric voltage can be categorized as an impulse.

From the test results with the same weight and height, the output voltage for one element was inconsistent. The 4 x 4 x 10 $\mathrm{cm}$ acrylic column in Fig. 8, which was used to adjust the fall path above the piezoelectric, could not guarantee the piezoelectric response consistency. 


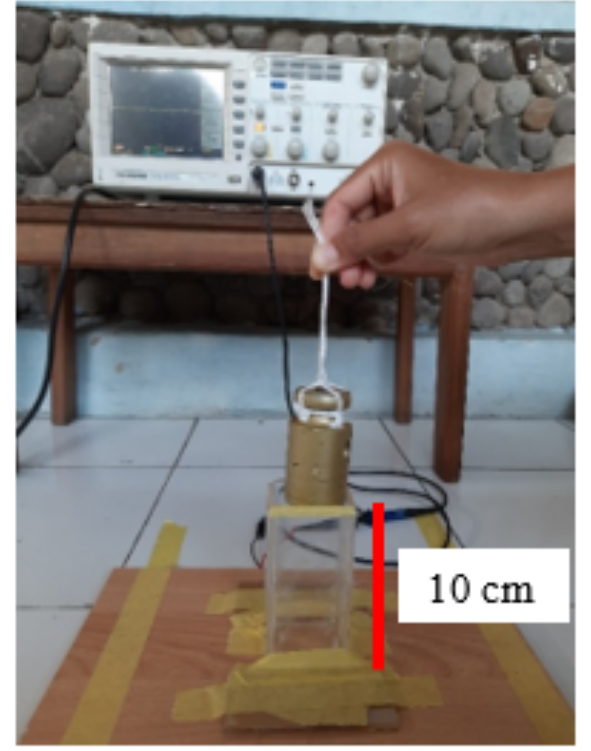

Fig. 8 Retrieval of data on the characteristics of the piezoelectric output voltage. (a)

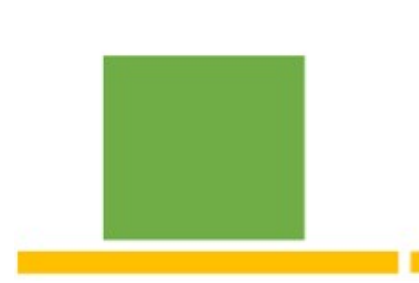

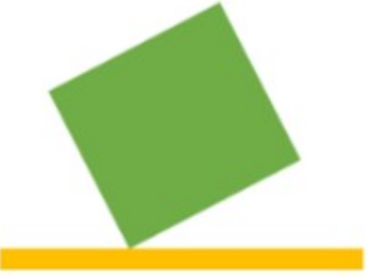

(b)
Fig. 9 The corner of the weight load on the parquet surface: (a) flat surface and (b) angular surface.

$$
\begin{gathered}
I=F \cdot \Delta t \\
I=\mathrm{m} \cdot \mathrm{g} \cdot \Delta t \\
I=0.5 \mathrm{~kg} \times 9.8 \frac{\mathrm{m}}{\mathrm{s}^{2}} \times 1 \mathrm{sec} \\
=4.9 \mathrm{~kg} \cdot \mathrm{m} / \mathrm{sec}
\end{gathered}
$$

Based on (3), the piezoelectric impulse response is affected by force received and the piezoelectric time interval when receiving the force. If the force is greater and the time interval is longer when receiving the force, the impulse will be more significant. Fig. 9 illustrates the weight's drop angle on the parquet surface in which Fig. 9(a) shows the flat surface and Fig. 9(b) shows the angular surface.

Based on (5), the differences of angle or the surface of an object with force will affect the pressure received by another object's surface. The relationship between force $(F)$ with the cross-sectional area or surface area $(A)$ is inversely proportional. The wider the cross-sectional area or surface impacted by pressure, the smaller the force generated. In contrast, the narrower the cross-sectional area, the greater the force generated. Hence, there is a correlation between the angle of dropped weights with the piezoelectric voltage response. When the weights drop precisely at 90-degree angles
TABLE II

PIEZOELECTRIC RESONANCE FREQUENCY SPECIFICATIONS

\begin{tabular}{|c|c|}
\hline Components & Resonant Frequency (Hz) \\
\hline 7BB-12-9 & $9.0 \mathrm{k} \pm 1.0 \mathrm{kHz}$ \\
\hline $7 \mathrm{BB}-15-6$ & $6.0 \mathrm{k} \pm 1.0 \mathrm{kHz}$ \\
\hline $7 \mathrm{BB}-20-3$ & $3.6 \mathrm{k} \pm 0.6 \mathrm{kHz}$ \\
\hline $7 \mathrm{BB}-27-4$ & $4.6 \mathrm{k} \pm 0.5 \mathrm{kHz}$ \\
\hline $7 \mathrm{BB}-35-3$ & $2.8 \mathrm{k} \pm 0.5 \mathrm{kHz}$ \\
\hline 7BB-35-3L0 & $2.8 \mathrm{k} \pm 0.5 \mathrm{kHz}$ \\
\hline 7BB-41-2 & $2.2 \mathrm{k} \pm 0.3 \mathrm{kHz}$ \\
\hline 7NB-31R2-1 & $1.3 \mathrm{k} \pm 0.5 \mathrm{kHz}$ \\
\hline VSB35EW-0701B & $950 \pm 150 \mathrm{~Hz}[$ Lowest] \\
\hline VSB50EW-0301B & $400 \pm 150 \mathrm{~Hz}[$ Lowest] \\
\hline
\end{tabular}

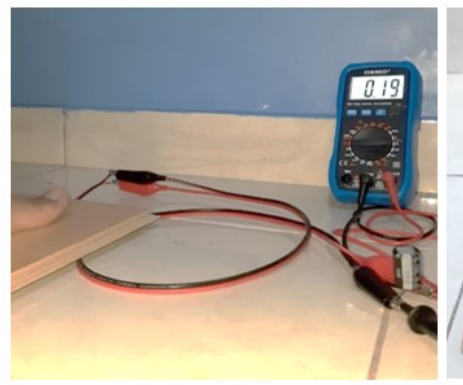

(a)

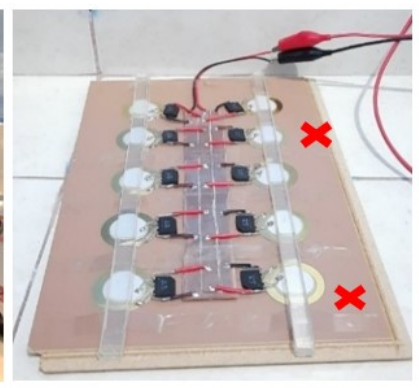

(b)
Fig. 10 (a) Capacitor charging test and (b) damaged piezoelectric elements.

perpendicular to the parquet surface, as shown in Fig. 9(a), the period is more extended than when the weights drop and form an angle, as shown in Fig. 9(b). The longer the period, the lower the frequency; the shorter the period, the higher the frequency.

$$
p=F / A \text {. }
$$

The piezoelectric used in this experiment was a piezoelectric buzzer with a dimension of $35 \mathrm{~mm}$, which is usually used as a speaker or buzzer. The frequency of using piezoelectric speakers was following [20] as in Table II. The operating frequency range was at $400 \mathrm{~Hz}$ to $9 \mathrm{kHz}$, or, in other words, the piezoelectric has high-frequency sensitivity. The characteristic data found that the piezoelectric used was more sensitive to high frequencies or with the same load weight. A slight pressure angle resulted in a short period of pressure and a higher impulse voltage amplitude. The measurement of the output voltage characteristics can also be used to determine the specifications of the power converter.

\section{B. Measurement Results of Energy Harvesting System}

Charging the capacitor with the proposed method is shown in Fig. 10. The voltage across the capacitor increases with each element's addition, although the increase is not an absolute linear. Each additional element was observed to increase the capacitor voltage by $0.1 \mathrm{~V}$. The highest results were in the $10-$ element parallel in which the capacitor voltage reached $0.53 \mathrm{~V}$. As the result, two elements were damaged at the terminals, as shown in Fig. 10(b). That condition was discovered after testing the module with 10- elements; thus, the reported test data was adjusted to the elements that were still in a good condition. Fig. 11 shows the calculation and measurement differences even 


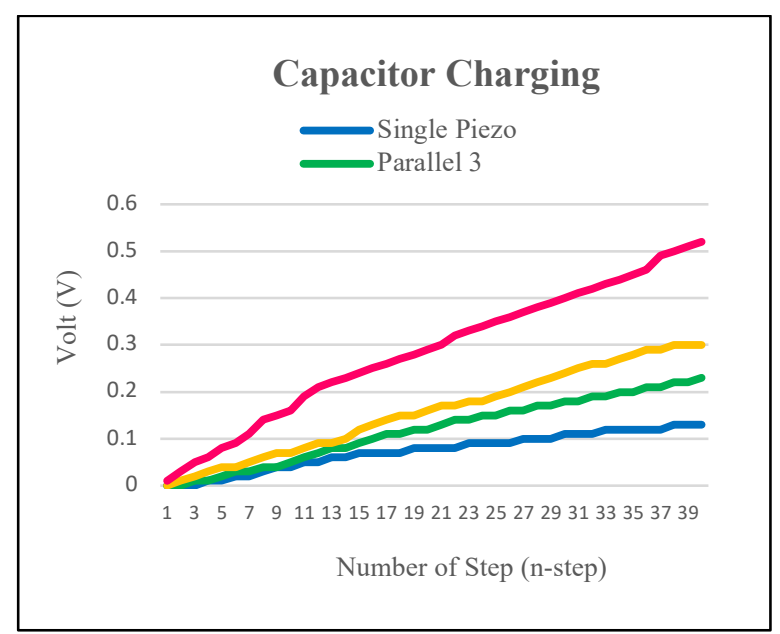

Fig. 11 Capacitor charging measurement.

though two elements are damaged. According to the calculation, the eight elements that are still in a good condition should have produced a voltage of $0.8 \mathrm{~V}$ with an increase of 0.1 $\mathrm{V}$ for each additional element. However, in the actual condition, the capacitor voltage could only reach $0.52 \mathrm{~V}$.

The charging experiment can also be calculated from this capacitor, the energy converted, and the energy generated from the PEHS. The energy converted was following (1) the potential energy from the footsteps of the piezoelectric energy harvesting module. Bodyweight $(m)$ for the test load was $45 \mathrm{~kg}$. The thickness of the module $(h)$ from the floor surface was 14 $\mathrm{mm}$. Therefore, while the acceleration due to gravity $(g)$ was $9.8 \mathrm{~m} / \mathrm{s}^{2}$, the potential energy for each step could be calculated.

$$
\begin{gathered}
E p=m \cdot g \cdot h \\
=45 \mathrm{~kg} \times 9.8 \frac{\mathrm{m}}{\mathrm{s}^{2}} \times 0.014 \mathrm{~m} \\
=6.174 \mathrm{~kg} \cdot \mathrm{m}^{2} / \mathrm{s}^{2} \\
=6.174 \mathrm{~J} / \mathrm{step}
\end{gathered}
$$

Table III shows that one element has produced energy of $18.59 \mu \mathrm{J}$. At the same time, the proposed module has filled the capacitor with $297.4 \mu \mathrm{J}$ with a voltage that has reached $0.53 \mathrm{~V}$. Meanwhile, the energy generated from this piezoelectric energy-producing system was the energy in the capacitor with an indicator that was the value of the capacitor voltage. Therefore, greater voltage value indicates that the energy in the capacitor is also getting more significant.

$$
\begin{gathered}
W=\frac{\left(2200 \times 10^{-6}\right) \times(0.13 \mathrm{~V})^{2}}{2}=18.59 \mu \text { Joule } \\
W=\frac{18.59 \mathrm{Joule}}{40 \mathrm{steps}}=0.464 \mu \mathrm{J} / \mathrm{step}
\end{gathered}
$$

The results above suggest that the number of piezoelectric elements affects the energy output produced. The more the number of elements used, the more energy is generated. However, some factors influence the amount of energy produced. The multiple piezoelectric outputs are not linear to the piezoelectric number because the energy transformation
TABLE III

CAPACITOR CHARGING ENERGY

\begin{tabular}{|c|c|c|}
\hline Configuration & Total Energy $(\boldsymbol{\mu J})$ & Energy Each Step $(\boldsymbol{\mu J})$ \\
\hline Single Piezo & 18.59 & 0.46475 \\
\hline Parallel 3 & 58.19 & 1.45475 \\
\hline Parallel 6 & 99 & 2.475 \\
\hline Parallel 8 & 297.44 & 7.436 \\
\hline \multicolumn{3}{|c|}{ TABLE IV } \\
POTENTIAL ENERGY THAT CAN BE GENERATED
\end{tabular}

\begin{tabular}{|c|c|c|}
\hline $\begin{array}{c}\text { Number of } \\
\text { Human } \\
\text { Activities }\end{array}$ & $\begin{array}{c}\text { Number of } \\
\text { Stairs }\end{array}$ & Harvested Energy (mJ) \\
\hline \multirow{3}{*}{1,000} & 15 & 111.54 \\
\cline { 2 - 3 } & 25 & 185.9 \\
\cline { 2 - 3 } & 30 & 223.08 \\
\hline
\end{tabular}

variations of the piezoelectric elements are not the same even with the same load and way of receiving pressure. In addition, another influencing factor is the uneven distribution of pressure at each step. However, the simple technique applied in this paper could harvest the energy of $7.436 \mu \mathrm{J}$ for each step and $297.4 \mu \mathrm{J}$ of total energy with 40 footsteps. This amount of energy can be used as an alternative to the power of IoT sensors. In the next section, the energy analysis of piezoelectric energyproducing systems as an alternative to sensor power in IoT will be discussed.

\section{Utilization of Energy Harvesting Systems for Sensor Devices in $I o T$}

In Table III, the energy produced by PEH module is 297.44 $\mu \mathrm{J}$ of energy, or the average energy of footing is $7.436 \mu \mathrm{J}$. These results can be used as an alternative to supply the load. The loads supplied in this context are low-power loads such as sensor devices on the IoT. The calculating energy sources with the time or duration of energy use is given by (7).

$$
\begin{aligned}
& W=P . t \\
& t=\frac{W}{P}
\end{aligned}
$$

where $W$ is electrical energy in joules $(\mathrm{J}), P$ is the electric power that comes from the voltage and current of the sensor device in watt (W), and $t$ is the operating time in seconds or minutes. The application is on the staircase of the building. The proposed module that needs to be considered is the number of steps and human activities in the staircase.

Assuming that each floor in the three buildings has a different number of stairs, each containing 1,000 people who simultaneously use those stairs with the average energy of each step being $7.436 \mu \mathrm{J}$, the potential energy generated is presented in Table IV. Based on Table IV, the first building with 15 stairs per floor has a potential energy of 111.54 ç. The second building with 25 stairs per floor has a potential energy of 185.9 $\mathrm{mJ}$. Meanwhile, the third building with 30 stairs per floor has a potential energy of $223.08 \mathrm{~mJ}$. Following (7) and using Table III with the potential energy of $223.08 \mathrm{~mJ}$, the obtained data when the power supply or the duration of the IoT sensor device can be seen in Table V. 
TABLE V

Piezoelectric Energy Harvesting System AS IoT SEnSOR POWER SupPly

\begin{tabular}{|l|c|c|c|c|}
\hline \multicolumn{1}{|c|}{ Device } & Voltage & Current & Power Consumption & Time Operation (Minutes) \\
\hline HC SR505 PIR Sensor & $4.5-20 \mathrm{~V}$ & $<60 \mu \mathrm{A}$ & Max. 1,200 $\mu \mathrm{W}$ & 3.10 \\
\hline $\begin{array}{l}\text { APDS-9960 Proximity, Gesture, Ambient } \\
\text { Light Sensor }\end{array}$ & $2.4-3.6 \mathrm{~V}$ & $0.2 \mathrm{~mA}$ & $0.72 \mathrm{~mW}$ & 5.16 \\
\hline $\begin{array}{l}\text { DHT11 } \\
\text { Standby) }\end{array}$ & $3.5-5.5 \mathrm{~V}$ & $60 \mu \mathrm{A}$ & $330 \mu \mathrm{W}$ & 11.27 \\
\hline RIOT-001 Environmental Sensor Board & Max. 5.5 V & $16.5 \mu \mathrm{A}$ & $90.75 \mu \mathrm{W}$ & 40.97 \\
\hline BMP085 Barometric Pressure Sensor & $1.8-3.6 \mathrm{~V}$ & $5 \mu \mathrm{A}$ & $18 \mu \mathrm{W}$ & 206.56 \\
\hline BMP180 Atmospheric Pressure Sensor & $3.3-5 \mathrm{~V}$ & $3 \mu \mathrm{A}$ & $15 \mu \mathrm{W}$ & 247.87 \\
\hline
\end{tabular}

The energy produced by the PEHS can be used as an alternative to the power supply for the sensor devices on the IoT, as presented in Table V. The sensor chosen was a sensor used for indoor purposes like recognizing human activities, air quality, and air pressure. The HC SR505 PIR sensor is the sensor with the shortest time supplied with a piezoelectric energy generating system from selected sensors. In contrast, the BMP180 sensor has the longest supply time.

\section{CONCLUSION}

Piezoelectric buzzer $35 \mathrm{~mm}$ output is an impulsive category with a minimum voltage characteristic of $8 \mathrm{~V}$ and a maximum of $25 \mathrm{~V}$. This can be used as a reference in specific converters for better energy harvester. Based on the characteristic test, the $35 \mathrm{~mm}$ piezoelectric buzzer has more sensitivity to highfrequency impulses. The proposed PEHS has produced 18.59 $\mu \mathrm{J}$ of energy for a single element, $58.19 \mu \mathrm{J}$ for three elements, $99 \mu \mathrm{J}$ for six elements, and $297.4 \mu \mathrm{J}$ for eight elements with an average energy of $7.436 \mu \mathrm{J}$ for each step.

The multiple piezoelectric outputs are not linear to the piezoelectric number because the energy transformation variations of the piezoelectric elements and the uneven distribution of pressure at each step influence the energy produced by $\mathrm{PEH}$. Based on the analysis carried out, this piezoelectric energy harvesting system can be an alternative sensor node power supply for WSN in IoT applications with different power supply time variations according to the supply needs of the sensor device. The consideration of the energy requirements of each operating mode on the WSN can also be a reference for the energy needed so that energy harvesters, especially piezoelectric energy harvesters, can be further optimized.

\section{REFERENCE}

[1] F. Mazunga and A. Nechibvute, "Ultra-Low Power Techniques in Energy Harvesting Wireless Sensor Networks: Recent Advances and Issues," Scientific African, Vol. 11, pp. 1-14, Mar. 2021.

[2] A. Chowdhury and D. De, "Energy-Efficient Coverage Optimization in Wireless Sensor Networks Based on Voronoi-Glowworm Swarm Optimization-K-Means Algorithm," Ad Hoc Networks, Vol. 122, pp. 116, Nov. 2021

[3] A.A. Babayo, M.H. Anisi, and I. Ali, "A Review on Energy Management Schemes in Energy Harvesting Wireless Sensor Networks," Renewable and Sustainable Energy Reviews, Vol. 76, pp. 1176-1184, Sep. 2017.

[4] C. Prommak and S. Modhirun, "Optimal Wireless Sensor Network Design for Efficient Energy Utilization," Journal of Computer Science, Vol. 8, No. 1, pp. 149-158, Nov. 2011.
[5] S. Balaji, M. Anitha, D. Rekha, and D. Arivudainambi, "Energy Efficient Target Coverage for a Wireless Sensor Network," Measurement, Vol. 165, Dec. 2020.

[6] S. Saravanan and M. Madheswaran, "Design of Low Power Multiplier with Reduced Spurious Transition Activity Technique for Wireless Sensor Network," 2008 Fourth International Conference on Wireless Communication and Sensor Networks, 2008, pp. 36-39.

[7] Q. Tan, Y. Liu, Y. Han, W. An, S. Ci, and H. Tang, "Energy Harvesting Aware Topology Control with Power Adaptation in Wireless Sensor Networks," Ad Hoc Networks, Vol. 27, pp. 44-56, Apr. 2015.

[8] S. Sachan, R. Sharma, and A. Sehgal, "Energy Efficient Scheme for Better Connectivity in Sustainable Mobile Wireless Sensor Networks," Sustainable Computing: Informatics and Systems, Vol. 30, Jun. 2021.

[9] Z. Huang, Q. Niu, S. Xiao, and T. Li, "Energy Harvesting Algorithm Considering Max Flow Problem in Wireless Sensor Networks," Computer Communications, Vol. 150, pp. 626-633, Jan. 2020.

[10] J. Ortiz, N. Zabala, P. Monje, V. Cokonaj, and G. Aranguren, "Energy Generation Based on Piezoelectric Transducers," Renewable Energy and Power Quality Journal, Vol. 1, No. 11, pp. 245-250, Mar. 2013.

[11] B. Khemmanee and D. Isarakorn, "Low-Cost Energy Management Circuit Base on Primary Feedback Self-Oscillating Flyback Converter for Piezoelectric Energy Harvesting," 2015 18th International Conference on Electrical Machines and Systems (ICEMS), 2015, pp. 1035-1038.

[12] L.B. Kong, T. Li, H.H. Hng, F. Boey, T. Zhang, and S. Li, Waste Energy Harvesting. Berlin, Germany: Springer Berlin Heidelberg, 2014.

[13] I. Patel, "Ceramic Based Intelligent Piezoelectric Energy Harvesting Device," in Advances in Ceramics - Electric and Magnetic Ceramics, Bioceramics, Ceramics and Environment, C. Sikalidis, Ed. Rijeka, Croatia: InTech, 2011, pp. 133-154.

[14] A. Patil, M. Jadhav, S. Joshi, E. Britto, and A. Vasaikar, "Energy Harvesting Using Piezoelectricity," 2015 International Conference on Energy Systems and Applications, 2015, pp. 517-521.

[15] W.A. Ching, M.J. Geotina, N.S. Gora, R.J. Sucayre, R.V.M. Santiago, and J.M. Martinez, "Implementation of Piezoelectric Generator for Harvesting Energy for Different Types of Staircases with Automatic Switching Mechanism," 2018 IEEE 10th International Conference on Humanoid, Nanotechnology, Information Technology, Communication and Control, Environment and Management (HNICEM), 2018, pp. 1-6.

[16] G.J. Song, J.Y. Cho, K.-B. Kim, J.H. Ahn, Y. Song, W. Hwang, S.D. Hong, and T.H. Sung, "Development of a Pavement Block Piezoelectric Energy Harvester for Self-Powered Walkway Applications," Applied Energy, Vol. 256, pp. 1-6, Dec. 2019.

[17] G.J. Song, K.-B. Kim, J.Y. Cho, M.S. Woo, J.H. Ahn et al., "Performance of a Speed Bump Piezoelectric Energy Harvester for an Automatic Cellphone Charging System," Applied Energy, Vol. 247, pp. 221-227, Aug. 2019.

[18] J.Y. Cho, K.-B. Kim, W.S. Hwang, C.H. Yang, J.H. Ahn et al., "A Multifunctional Road-Compatible Piezoelectric Energy Harvester for Autonomous Driver-Assist LED Indicators with a Self-Monitoring System," Applied Energy, Vol. 242, pp. 294-301, May 2019.

[19] W. Hwang, K.-B. Kim, J.Y. Cho, C.H. Yang, J.H. Kim, G.J. Song et al., "Watts-Level Road-Compatible Piezoelectric Energy Harvester for a Self-Powered Temperature Monitoring System on an Actual Roadway," Applied Energy, Vol. 243, pp. 313-320, Jun. 2019.

[20] Piezoelectric Sound Components Application Manual, Murata Manufacturing Co., Ltd., Shibuya, Japan, 2012. 